\title{
Rat Model of Cecal Ligation and Puncture versus Colon Ascendens Stent Peritonitis: Comparative Study for Oxidative Stress
}

\author{
Lei Chen, Daiyin Cao, Enhe Liu, Chaoxing Xiao, Mengran Xiong, Qiuye Kou* \\ Department of ICU, the Sixth Affiliated Hospital of Sun Yet-sen University, Guangzhou, China \\ Email: *kouqiuye@126.com
}

How to cite this paper: Chen, L., Cao, D.Y., Liu, E.H., Xiao, C.X., Xiong, M.R. and Kou, Q.Y. (2017) Rat Model of Cecal Ligation and Puncture versus Colon Ascendens Stent Peritonitis: Comparative Study for Oxidative Stress. Advances in Infectious Diseases, 7, 80-92.

https://doi.org/10.4236/aid.2017.73009

Received: August 8, 2017

Accepted: September 16, 2017

Published: September 19, 2017

Copyright $\odot 2017$ by authors and Scientific Research Publishing Inc. This work is licensed under the Creative Commons Attribution International License (CC BY 4.0).

http://creativecommons.org/licenses/by/4.0/

\begin{abstract}
The CLP and CASP model as important research tools have been widely utilized in septic OS. In this study, we compare the oxidative stress condition of CLP and CASP rat models. Compared with sham operation group, infection condition and oxidative stress index were significantly different in CLP and CASP groups. Compared with CLP group, there was no significant difference in natural death rate, bacterial colony positive rate, infection condition, center venous oxygen saturation, and serum levels of TNF- $\alpha$ in the CASP group; whereas, MDA decreased significantly at 72 hours, T-SOD increased considerably at 12 and 72 hours after operation in the CASP group. The serum NO significantly decreased at all time-points except at 12 hours post-operation. Together, our study demonstrated the similarity of oxidative stress condition between CLP and CASP models. However, CASP rats had higher serum NO level than CLP rats.
\end{abstract}

\section{Keywords}

Sepsis, Oxidative Stress, Animal Model, Rat, CLP, CASP

\section{Introduction}

Sepsis refers to the systemic inflammatory response syndrome (SIRS) caused by infections [1], which is the common pathophysiological process of multiple diseases as a consequence of autoimmune injury mediated by large amount cytokines and inflammatory mediators [2]. Further development of sepsis results in severe conditions including septic shock, severe sepsis, multiple organ dysfunction syndromes (MODS), and even death. In recent years, the mortality rate of sepsis in the young population decreased [3] because of the implementation of 
"Surviving Sepsis Campaign International Guidelines for the management of severe sepsis and septic shock" [4] [5] [6]. However, the statistical analysis from ICU shows that the mortality rates of sepsis and septic shock were still as high as $30 \%$ and $60 \%$, respectively [7] [8] [9].

The pathogenesis mechanism of sepsis is very complicated; the major pathophysiological processes include cytokine storm, inflammatory waterfall-like reaction, enteral bacterial translocation, intestinal-derived endotoxin, the interplay between coagulation and inflammation systems, oxidative stress (OS), immune cell apoptosis, microcirculation and mitochondrial dysfunction [10] [11] [12] [13]. The ideal sepsis animal model has been widely utilized, such as endotoxemia model, cecal ligation and puncture (CLP) model, and colon ascendens stent peritonitis (CASP) model [14]. CLP and CASP were the favorite models because they could simulate the pathophysiological process of human sepsis. Meanwhile, the severity of sepsis could be well controlled by manipulating the punctures in CLP model or drainages in CASP model [15]. Furthermore, Maier et al. [15] have suggested that CASP closely mimics the clinical course of diffuse peritonitis, whereas CLP more closely resembles intra-abdominal abscess formation.

However, most of the comparative studies on these models mainly focused on the differences in natural death rate or inflammation severity. Though the CLP and CASP models have been intensively used for studying the oxidative stress of sepsis [16] [17], the differences between them have not yet been compared.

\section{Methods}

\subsection{Experimental Animal}

One hundred and fifty eight-months-old male SD rats (grade SPF), weighing between 250 and $280 \mathrm{~g}$, were obtained from animal facility of Traditional Chinese Medicine University of Guangzhou (Certificate No. 44005800000296). The rats were raised in the clean grade feeding room of the laboratory animal center on the north campus of Sun Yet-sen University (License No. SYXK2012-0081). The room temperature of the feeding room ranged between $18^{\circ} \mathrm{C}$ and $25^{\circ} \mathrm{C}$, and the relative humidity was between $45 \%$ and $55 \%$. The rats took food and water freely, and the rat food was from the animal facility of Sun Yet-sen University. The pads for the feeding case were changed every two days, and the rats were used for experiment one week later. All the experiments were approved by the Experimental Animal Ethics Committee of Sun Yet-sen University.

\subsection{Establishment of Rat Model}

Sham operation group: The rats fasted from food for 12 hours but drank water freely before the operation. They were given anesthesia by intraperitoneal injection of $10 \%$ chlorine aldehyde at a dose of $0.3 \mathrm{~mL} / 100 \mathrm{~g}$ body weight, and the abdominal cavity was opened along the middle line after disinfection and depilation; the cecum and ascending colon were freed from mesenterium after full ex- 
posure and injury to blood vessels was carefully avoided. Then cecum and ascending colon were placed back to the original position, and the incision was closed layer by layer.

CLP group: The operation was similar to that of the sham operation group, except the cecum was ligated in the middle of the root with 5/0 surgical suture. The perforated puncture at the cecum $1.0 \mathrm{~cm}$ distal to ligation was made with 18 $G$ needle, and the blood vessel was avoided. The small amount of intestinal content overflow was forced out by cotton swab pressure to ensure the success of puncture. Then, the cecum was placed back to the original position, and the incision was closed layer by layer [18].

CASP group: The beginning of the operation was similar to that of the sham operation group. After exposure of the ascending colon, a 18 GA venous indwelling needle (BD, US) was stitched through the antimesenteric wall into the lumen of the ascending colon and then fixed with 7/0 surgical suture placed approximately $10 \mathrm{~mm}$ from the ileocecal valve. Consecutively, the inner needle of the stent was removed, and the stent was cut at the prepared site. To ensure proper intraluminal positioning of the stent, the stool was milked from the cecum into the ascending colon and the stent until a small drop of stool appeared. The ascending colon and indwelling needle were placed back to the original position, and the incision was closed layer by layer [19] [20].

Normal saline solution was injected subcutaneously into each rat at the concentration of $5 \mathrm{~mL} / 100 \mathrm{~g}$ body weight after the operation, and the rats were placed back in the cages; the body temperature was maintained by electrically heated blanket until they woke from anesthesia. The physical activity of the rats was observed after anesthetic recovery, and the food and water were provided for a free feed. The conditions of the rats were recorded every 12 hours.

\subsection{Research Strategy}

One hundred and fifty SD rats were randomly classified into three groups: CLP $(n=50)$, CASP $(n=50)$, and sham operation groups $(n=50)$. Ten rats from each group were randomly selected after the operation as normal feeding and observed for one week to record the time of death. The rest of the rats were analyzed by re-opening the abdomen for direct observation, four rats from each group were randomly selected at the postoperative time of 12 hours, 24 hours, 48 hours, and 72 hours, respectively, under anesthesia by intraperitoneal injection of $10 \%$ chlorine aldehyde at a dose of $0.3 \mathrm{~mL} / 100 \mathrm{~g}$ body weight. Venous blood of 7 to $9 \mathrm{~mL}$ was collected under the sterile condition from thoroughly exposed inferior vena cava. Then, the rats were sacrificed by decapitating. The blood samples were used for bacterial culture assessments for inflammatory mediators and oxidative indicators. The ileum tissue of 2 to $3 \mathrm{~cm}$ was cut off and placed in Bouin solution (Spectrum Chemicals \& Laboratory Products, Shanghai, China) and used for specimen section preparation. 


\subsection{Laboratory Assessment and Methods}

Blood samples: $2 \mathrm{~mL}$ blood sample was spread onto Columbia blood agar (Becton Dickinson, Heidelberg, Germany) and incubated at $350^{\circ} \mathrm{C}$ to $37^{\circ} \mathrm{C}$ overnight; the strains and colonies of the bacterium were assessed by typical bacterial growth method. Another $2 \mathrm{~mL}$ blood sample was transferred to Heparin anticoagulant tube and analyzed by NAVO CCX blood gas analyzer (NAVO Biomedical, Waltham, US). The rest of the blood samples were stored at room temperature for two hours before centrifugation at a speed of $3400 \mathrm{rpm}$ for $15 \mathrm{mi}-$ nutes, and then the serums were used for IL- 6 , TNF- $\alpha$, MDA, NO, and T-SOD quantitation. The serum levels of IL- 6 and TNF- $\alpha$ were measured by ELISA, MDA was measured by thiobarbituric acid (TBA) colorimetry, and NO and T-SOD were measured by the method of nitrate reductase activity determination and xanthine oxidase activity determination, respectively. Kits for IL- 6 and TNF- $\alpha$ quantitation were from Ray Biotech (US); and kits for MDA, NO, and T-SOD quantitation were from Nanjing Jiancheng Bioengineering Institute (Nanjing, China). All the measurements were carried out according to the manufacturer's instruction.

Ileum tissue samples: The ileum tissue was separated and repeatedly washed with an isotonic saline solution, followed by fixation in Bouin solution for 48 hours. The ileum tissues were cut into pieces of $1 \mathrm{~cm}$ and embedded in paraffin for consecutive sections, the specimen was $5 \mu \mathrm{m}$ thick and was used for HE staining; the pathological morphology was observed under a microscope (Nikon, Tokyo, Japan).

\subsection{Statistical Analysis}

The data are presented as mean \pm SD and processed by SPSS 13.0 software. The comparisons among multiple groups were analyzed by ANOVA, and the inter-group comparison was conducted by LSD analysis. Survival analysis was conducted by Kaplan-Meier, and inter-group comparison regarding survival was performed by log-rank analysis. $\mathrm{P}<0.05$ was considered as statistical significance.

\section{Results}

\subsection{Survival Analysis}

The survival rate of sham operation group within one week was $100 \%$, whereas, it was $40 \%$ and $60 \%$ for CLP and CASP groups, respectively. There was a significant difference in survival rate between the sham operation and CLP or CASP group $(\mathrm{P}<0.05)$, there was no significant difference between the CLP and CASP groups $(\mathrm{P}>0.05)$ (Figure 1$)$.

\subsection{Severity of Sepsis}

\section{- Abdominal cavity infection}

Chills, reduced activity, reduced food consumption, the closing of eyes, curl- 


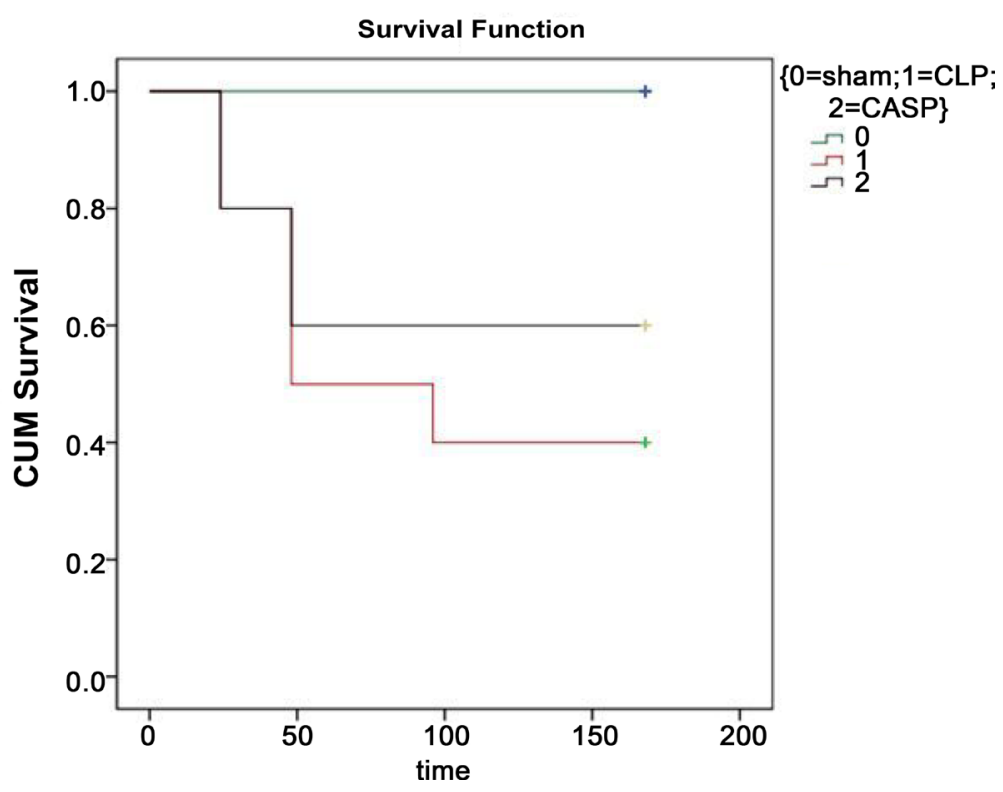

Figure 1. Survival analysis in the sepsis models. CLP was performed by ligation of the cecum and punctures according to the protocol of Wichtermann et al. [17]. CASP was performed by insertion of a 16-gauge stent in the ascending colon of the experimental rats according to the protocol of Zantl et al. [18]. Sham operations were performed by laparotomy without puncturing and ligation. Groups are depicted as indicated. Survival was $100 \%$ in the sham group, $40 \%$ in the CLP group, and $60 \%$ in the CASP group. No significant differences were found between CLP and CASP.

ing up of the body, piloerection, increased eye secretions, oliguria, and yellow urine were commonly observed in the rats from the CLP and CASP groups after operation; rats from the CLP group had even longer lasting symptoms. However, the rats from the sham operation group had none of the above symptoms.

It was observed from abdominal open operation that the swelling, congestion, adhesion, hemorrhage, reduced intestinal peristalsis were found in the rats from the CLP and CASP groups 12 hours after the operation; the aggravated signs were observed 24 and 48 hours after the operation. Moreover, these signs were more persistent in the rats from the CLP group. The rats that survived for 72 hours after operation had alleviated symptoms. Also, the congestion and gangrene at the distal parts of cecum in the CLP group could be found at different time points whereas the rats from the sham operation group had no such manifestation (Figure 2).

\section{- Venous blood bacterial culture}

There was no bacterial colony formed in the venous blood sample from rats in the sham operation group compared to the rats in the CLP and CASP groups, which had bacterial colonies mostly at 24 and 48 hours after the operation. The positive rate of bacterial culture was 100\% for CLP group at 24 and 48 hours and CASP at 24 hours. The major strains of the bacterium were Escherichia coli, Streptococcus spp., and bacteroidetes (Table 1).

\section{- Tissue oxygen metabolism}

The blood lactic acid concentration was significantly increased in the CLP at 



Figure 2. Abdominal cavity infection in each group. Four rats from each group underwent the open abdominal surgery under anesthesia by intraperitoneal injection of $10 \%$ chlorine aldehyde at a dose of $0.3 \mathrm{~mL} / 100 \mathrm{~g}$ body weight, at 12 hours, 24 hours, 48 hours and 72 hours after sepsis model establishment. The abdominal cavity was thoroughly exposed, and the typical photos of each group were presented. The abdominal adhesion, intestinal congestion, and edema could be observed in CLP at postoperative 24 and 48 hours; whereas, similar manifestations were presented at postoperative 24 hours in CASP. In addition, the obvious gangrene could be observed at the ligation part of ileum, indicated with an arrow.

each time point compared with the sham operation group $(\mathrm{P}<0.05)$. Also, the lactic acid increased considerably in CASP group from 12 hours to 48 hours but was restored at 72 hours post-operation. Compared with CLP group, the blood lactic acid level in CASP group was of no significant difference at 24 hours (P > $0.05)$ but significantly decreased after postoperative 48 hours $(\mathrm{P}<0.05)$.

In comparison with sham operation group, the central venous oxygen saturation in the CLP and CASP groups was significantly decreased $(\mathrm{P}<0.05)$ though there was no obvious difference between the two groups $(\mathrm{P}>0.05)$ (Table 2).

\section{- Inflammation mediators}

The serum concentration of IL- 6 and TNF- $\alpha$ was significantly increased at each time point in the rats from CLP and CASP groups compared with those from the sham operation group $(\mathrm{P}<0.05)$ (Table 2). However, there was no noticeable difference between the two groups $(\mathrm{P}>0.05)$, except that the serum IL-6 was decreased in the CASP group at 72 hours $(\mathrm{P}<0.05)$.

The peak concentrations of IL- 6 and TNF- $\alpha$ were observed at 24 hours, and lasted till 48 hours after operation; a significant decline was only observed after 72 hours in the CLP group. The dynamic alteration of IL- 6 and TNF- $\alpha$ in the CASP group was similar to that in CLP group $(\mathrm{P}>0.05)$, except that the decline 
Table 1. The blood bacterial culture results.

\begin{tabular}{|c|c|c|c|c|}
\hline \multicolumn{2}{|c|}{ Group } & \multirow{2}{*}{$\begin{array}{c}\begin{array}{c}\text { Animal number with } \\
\text { positive bacterial culture }\end{array} \\
0 / 4\end{array}$} & \multirow{2}{*}{$\begin{array}{c}\text { Strains of bactrium } \\
-\end{array}$} & \multirow{2}{*}{$\begin{array}{c}\text { Colony numbe } \\
\text { of bacterium }\end{array}$} \\
\hline Sham & $12 \mathrm{~h}$ & & & \\
\hline & $24 \mathrm{~h}$ & $0 / 4$ & - & \\
\hline & $48 \mathrm{~h}$ & $0 / 4$ & - & \\
\hline & $72 \mathrm{~h}$ & $0 / 4$ & - & \\
\hline \multirow[t]{10}{*}{ CLP } & $12 \mathrm{~h}$ & $1 / 4$ & Enterobacteria & 1 \\
\hline & & & Enterobacteria & 4 \\
\hline & $24 \mathrm{~h}$ & $4 / 4$ & Enterococcus faecalis & 4 \\
\hline & & & Bacteroidetes & 4 \\
\hline & & & Enterobacteria & 4 \\
\hline & $48 \mathrm{~h}$ & $4 / 4$ & Enterococcus faecalis & 3 \\
\hline & & & Bacteroidetes & 2 \\
\hline & & & Enterobacteria & 2 \\
\hline & $72 \mathrm{~h}$ & $2 / 4$ & Enterococcus faecalis & 1 \\
\hline & & & Bacteroidetes & 1 \\
\hline \multirow[t]{7}{*}{ CASP } & $12 \mathrm{~h}$ & $1 / 4$ & Enterobacteria & 1 \\
\hline & & & Enterobacteria & 4 \\
\hline & $24 \mathrm{~h}$ & $4 / 4$ & Enterococcus faecalis & 2 \\
\hline & & & Bacteroidetes & 4 \\
\hline & $48 \mathrm{~b}$ & $2 / 4$ & Enterobacteria & 2 \\
\hline & 4011 & $2 / 4$ & Bacteroidetes & 2 \\
\hline & $72 \mathrm{~h}$ & $0 / 4$ & - & \\
\hline
\end{tabular}

Table 2. Oxygen metabolism and inflammatory mediator comparison among groups.

\begin{tabular}{|c|c|c|c|c|c|}
\hline \multicolumn{2}{|c|}{ Group } & \multirow{2}{*}{$\begin{array}{c}\mathrm{Lac}(\mathrm{mmol} / \mathrm{L}) \\
3.550 \pm 0.480\end{array}$} & \multirow{2}{*}{$\begin{array}{c}\text { Scvo2 (\%) } \\
78.90 \pm 4.84\end{array}$} & \multirow{2}{*}{$\begin{array}{l}\text { IL-6 }(\mathrm{pg} / \mathrm{ml}) \\
127.6 \pm 19.2\end{array}$} & \multirow{2}{*}{$\begin{array}{c}\text { TNF- } \alpha(\mathrm{pg} / \mathrm{ml}) \\
25.9 \pm 3.5\end{array}$} \\
\hline Sham & $12 \mathrm{~h}$ & & & & \\
\hline & $24 \mathrm{~h}$ & $4.000 \pm 0.424$ & $72.75 \pm 5.25$ & $151.8 \pm 49.3$ & $26.0 \pm 2.8$ \\
\hline & $48 \mathrm{~h}$ & $4.100 \pm 0.469$ & $75.50 \pm 5.20$ & $148.3 \pm 27.3$ & $26.9 \pm 2.9$ \\
\hline & $72 \mathrm{~h}$ & $4.000 \pm 0.726$ & $78.90 \pm 4.84$ & $152.1 \pm 38.1$ & $25.0 \pm 2.4$ \\
\hline \multirow[t]{4}{*}{ CLP } & $12 \mathrm{~h}$ & $5.375 \pm 1.601^{*}$ & $66.05 \pm 5.16^{*}$ & $273.0 \pm 27.5^{\star}$ & $45.5 \pm 7.1^{*}$ \\
\hline & $24 \mathrm{~h}$ & $12.300 \pm 1.160^{\star} \Delta$ & $58.38 \pm 7.96^{*}$ & $1005.5 \pm 131.4^{\star} \Delta$ & $55.9 \pm 5.5^{\star} \Delta$ \\
\hline & $48 \mathrm{~h}$ & $11.975 \pm 0.954^{\star} \Delta$ & $59.13 \pm 7.86^{*}$ & $993.6 \pm 91.3^{*} \Delta$ & $49.7 \pm 4.3^{*}$ \\
\hline & $72 \mathrm{~h}$ & $10.625 \pm 1.735^{\star} \Delta$ & $57.13 \pm 8.06^{*}$ & $812.1 \pm 105.6^{*} \Delta \boldsymbol{\Delta} \&$ & $37.1 \pm 4.2^{\star} \Delta \boldsymbol{\Delta} \&$ \\
\hline \multirow[t]{4}{*}{ CASP } & $12 \mathrm{~h}$ & $5.575 \pm 0.998^{*}$ & $66.60 \pm 8.25^{\star}$ & $365.0 \pm 41.3^{*}$ & $45.7 \pm 6.7^{\star}$ \\
\hline & $24 \mathrm{~h}$ & $11.250 \pm 2.095^{\star} \Delta$ & $62.18 \pm 9.25^{\star}$ & $989.8 \pm 88.2^{\star} \Delta$ & $56.7 \pm 6.8^{\star} \Delta$ \\
\hline & $48 \mathrm{~h}$ & $9.600 \pm 1.564^{\star} \# \Delta$ & $60.48 \pm 9.46^{*}$ & $913.7 \pm 70.9^{\star} \Delta$ & $49.2 \pm 4.6^{*}$ \\
\hline & $72 \mathrm{~h}$ & $5.700 \pm 1.564 \# \boldsymbol{\Delta} \&$ & $64.13 \pm 7.58^{\star}$ & $444.8 \pm 46.3^{\star} \# \mathbf{\Delta} \&$ & $39.2 \pm 5.0^{\star} \boldsymbol{\Delta} \&$ \\
\hline
\end{tabular}

${ }^{\star}$ Comparison of CLP or CASP with the sham operation group at the same time point, i.e., ${ }^{\star} \mathrm{P}<0.05$ vs. sham; \# Comparison between CASP and CLP at the same time point. i.e., \#P $<0.05$ vs. CLP; $\Delta$ intra-group comparison between the time point of $24 \mathrm{~h} / 48 \mathrm{~h} / 72 \mathrm{~h}$ and $12 \mathrm{~h}$, i.e., $\Delta \mathrm{P}<0.05$ vs. $12 \mathrm{~h} ; \boldsymbol{\Delta}$ intra-group comparison between the time point of $48 \mathrm{~h} / 72 \mathrm{~h}$ and $24 \mathrm{~h}$, i.e., $\boldsymbol{\Delta} \mathrm{P}<0.05$ vs. $24 \mathrm{~h}$; \& intra-group comparison between $72 \mathrm{~h}$ and 48 h. i.e., $\& \mathrm{P}<0.05$ vs. $48 \mathrm{~h}$. 
at postoperative 72 hours was even more significant $(\mathrm{P}<0.05)$.

\subsection{Ileum Pathological Observation}

The morphology of ileum presented no significant difference between CLP and CASP groups at postoperative 12 hours, manifested as the integrated layers of ileum, with small amount of neutrophils or monocytes infiltration; the neutrophils infiltration was also found in mesangial adipose tissue. The increased neutrophils and monocytes infiltration was observed in each layer of the intestine in the rats from CLP and CASP groups at postoperative 24 hours; the mucosal edema, erosion, submucosal telangiectasia, and congestion were more significant in both groups, but more severe in the CLP group. The mucosal edema and erosion became severe in CLP group at postoperative 48 hours, while the inflammatory cells infiltration and mucosal edema were severe in CASP group; the erosion was not that significant. The mucosal atrophy in CLP and CASP was found 72 hours after the operation, and the inflammatory cells infiltration was still severe in CASP group (Figure 3).

\subsection{Oxidative Stress}

As shown in Figure 4, the serum levels of MDA and NO in CLP and CASP groups were increased at each time point compared with the sham operation group while the T-SOD level was significantly decreased $(\mathrm{P}<0.05)$. Compared with CLP, the serum level of MDA was significantly decreased at 72 hours after operation $(\mathrm{P}<0.05)$, while the serum level of T-SOD was increased at 12 and 72 hours after operation in the CASP group $(\mathrm{P}<0.05)$. Also, the serum level of NO was significantly decreased at all time points $(\mathrm{P}<0.05)$ except at postoperative 12 hours $(\mathrm{P}>0.05)$.

\section{Discussion}

The pathogenesis mechanism of sepsis is very complicated; it is a consequence of interplays among multiple pathological processes. The oxidative stress is one of important pathological mechanism, which had been verified with many sepsis animal models including CLP and CASP [21].

In the current study, the oxidative stress condition was compared in the two models, and it was found that the oxidative stress parameters such as MDA and NO were significantly increased in both CLP and CASP models 12 hours after operation compared with the sham operation group $(\mathrm{P}<0.05)$. However, the anti-oxidative T-SOD was decreased $(\mathrm{P}<0.05)$, which was consistent with the previously published literature [22] [23]. Meanwhile, the oxidative stress condition in the CLP and CASP groups was similar within 72 hours, and there was no significant difference between the two groups regarding MDA and T-SOD levels $(\mathrm{P}>0.05)$, but 72 hours later, it became greatly improved as shown by the decreased MDA $(\mathrm{P}<0.05)$ and increased T-SOD in the CASP group $(\mathrm{P}<0.05)$.

Furthermore, it was found that the serum NO level was significantly higher in 
CASP group than in CLP group $(\mathrm{P}<0.05)$, and this was the most significant difference between the two groups regarding oxidative stress. Serum NO level not only could reflect oxidative stress level but also the inflammatory reaction in an animal model. The high level of serum NO indicated that inflammatory mediators were higher in CASP group than in CLP group, agreeing with the findings of Maier et al. [15] that IL-12 and IFN- $\gamma$ levels were higher in CASP than in CLP model. The gangrene was observed in the cecum of CLP model in the current study, while the broad adherence was found in CASP model, indicating that

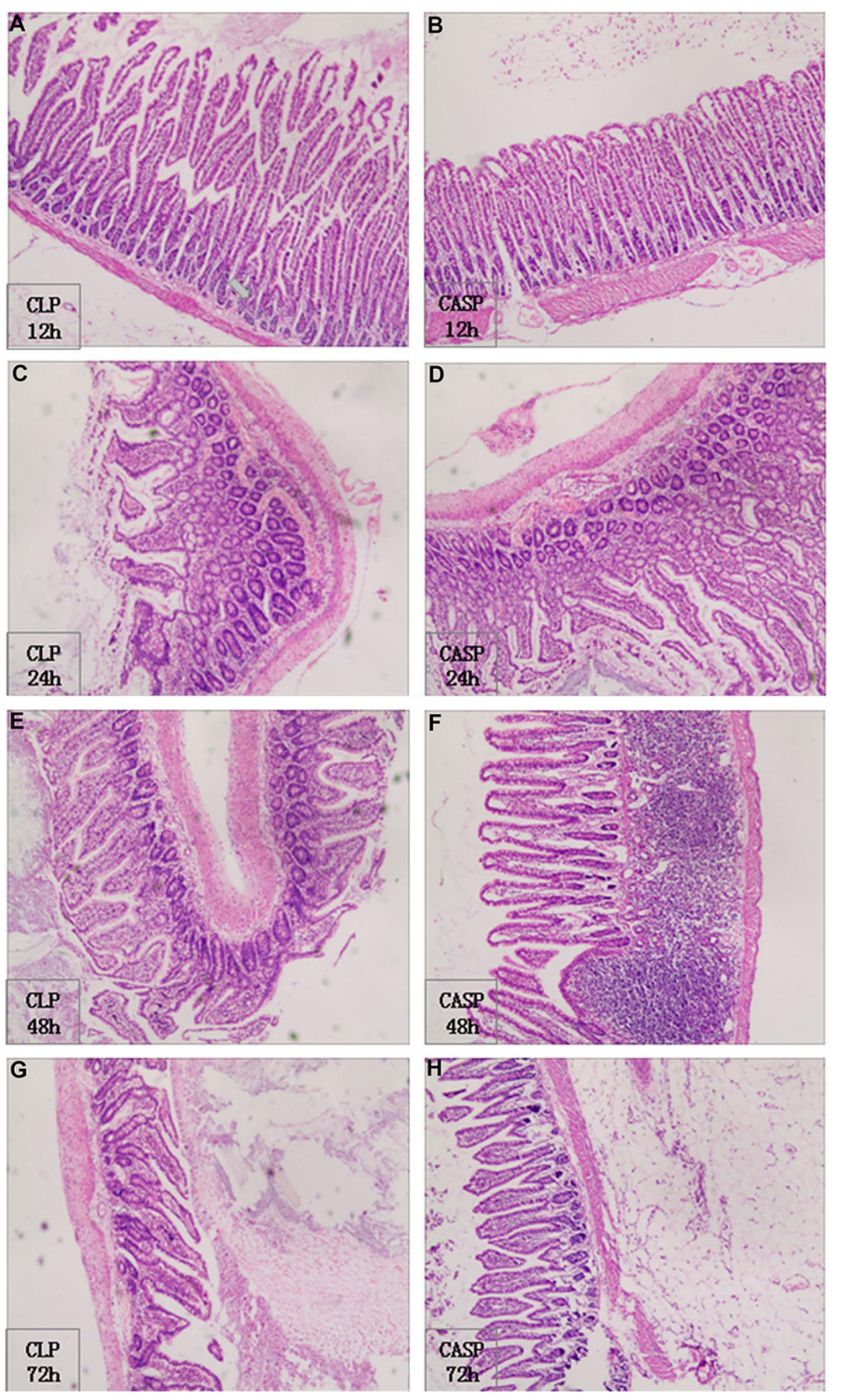

Figure 3. Histochemistry of ileum. HE staining of ileum cryosections was performed at $12 \mathrm{~h}, 24 \mathrm{~h}, 48 \mathrm{~h}$ and $72 \mathrm{~h}$ after surgery. Four mice per group were analyzed. Representative findings of each experimental group are shown. The neutrophils and monocytes infiltration into every layer of the intestine, obvious mucosal edema and erosion, submucosal blood vessel dilation and congestion was observed in CLP as well as in CASP rats. The manifestation was more significant at postoperative 24 hours in CLP compared with CASP. 


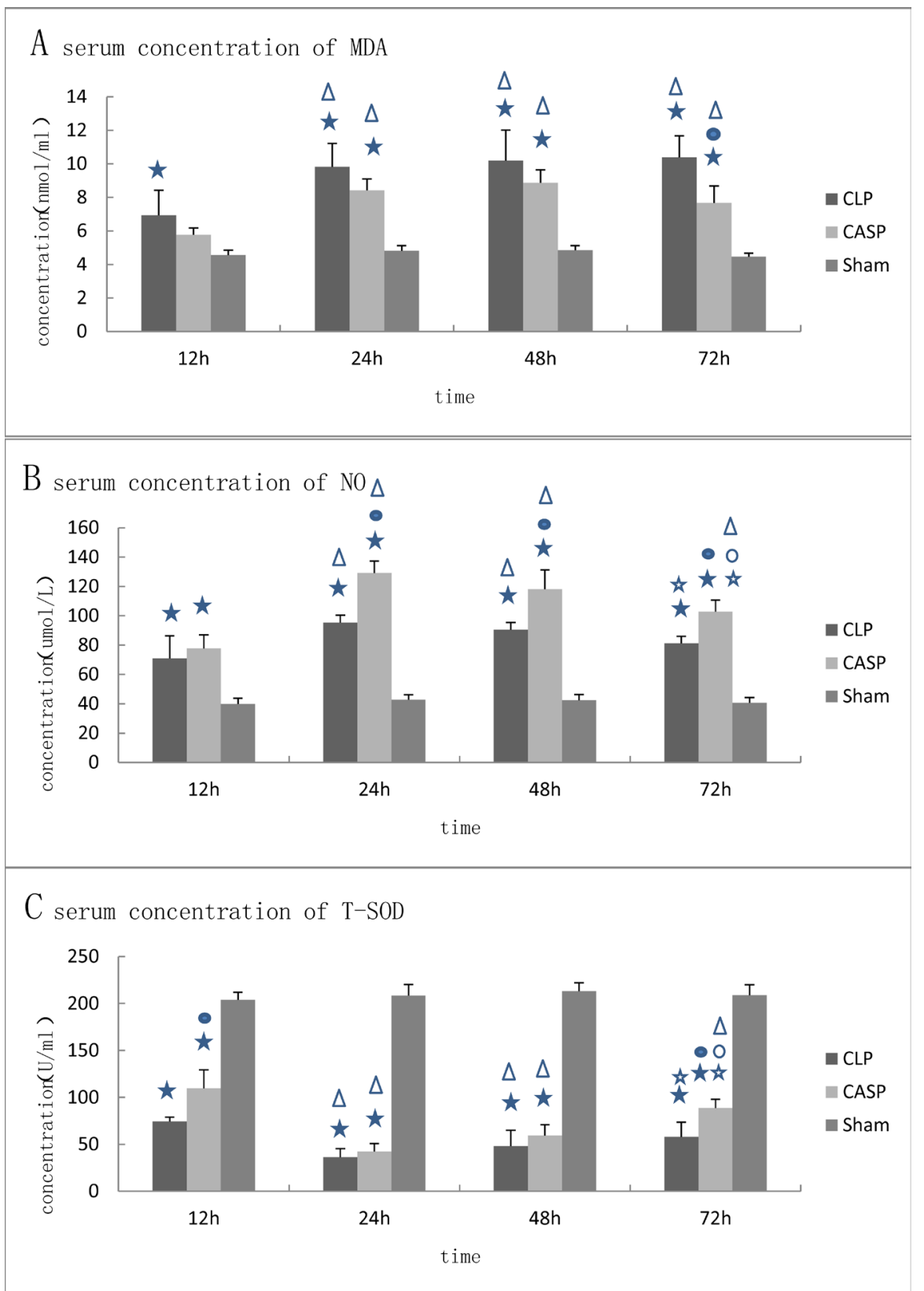

Comparison of CLP or CASP with the sham operation group at the same time point, i.e., $\mathrm{P}<0.05$ vs. sham; $\bullet$ Comparison between CASP and CLP at the same time point, i.e., $\mathrm{P}<0.05$ vs. CLP; $\Delta$ intra-group comparison between the time point of $24 \mathrm{~h} / 48 \mathrm{~h} / 72 \mathrm{~h}$ and $12 \mathrm{~h}$, i.e., $\mathrm{P}<0.05$ vs. $12 \mathrm{~h}$; is intra-group comparison between the time point of $48 \mathrm{~h} / 72 \mathrm{~h}$ and $24 \mathrm{~h}$, i.e., $\mathrm{P}<0.05 \mathrm{vs}$. $24 \mathrm{~h}$; Ointra-group comparison between $72 \mathrm{~h}$ and 48 h. i.e., $\mathrm{P}<0.05$ vs. $48 \mathrm{~h}$.

Figure 4. Comparison of oxidative stress in groups. Rats were sacrificed at the given time points. Blood was collected, and thibabituric acid (TBA)-colorimeter, nitrate reductase method and xanthine oxidase for MDA, NO and T-SOD was performed respectively according to the manufacturer's guidelines. Values are given as nanomole per milliliter. Four single experiments were performed in every group. Mean values \pm SEM are depicted as indicated. Figure A shows that compared sham operation group, high MDA values and the continuous increase was found in CLP and CASP animals. MDA levels after CASP were significantly lower $(\mathrm{P}<0.05)$ than those after CLP only at 72 hours. Figure B shows that compared with sham operation group, high NO values and continuous increase were found in CLP and CASP animals. NO was significantly altered except at postoperative 12 hours $(\mathrm{P}>$ $0.05)$; a significant decrease was observed at the other time points $(P<0.05)$. Figure $C$ shows that compared with sham operation group, low T-SOD values and the continuous increase was found in CLP and CASP animals. T-SOD levels after CASP were significantly higher $(\mathrm{P}<0.05)$ than those after CLP at 12 and 72 hours. 
CASP model simulated the pathological and physiological processes of diffuse peritonitis, whereas, CLP model simulated the process of intestine gangrene.

Based on the preliminary study and literature review [15], the CLP of single puncture at cecum and CASP of $18 \mathrm{GA}$ venous dwelling needle were adopted in the current study. The two models were compared based on the natural death rate, blood bacterial culture, ileum pathological morphology, tissue oxygen metabolism and inflammation mediators level. There was no significant difference between the two groups in terms of sepsis severity, especially within 72 hours. On the other hand, the difference in the oxidative stress was typical and significant in the two groups.

The ideal model of sepsis animal is usually characterized by high natural death rate, positive blood bacterial culture, severe inflammation reaction, and obvious organ functional damage [21], and the oxidative stress as one important mechanism of sepsis should be manifested in the animal model. Therefore, the oxidative stress was especially investigated in the two models which could provide the experimental basis for oxidative stress study. Also, this study could potentially help with the selection of cheap and ideal sepsis model in the future.

Both CLP and CASP models could simulate the clinical process of severe sepsis under inflammation or oxidative stress condition. However, CASP rats recovered faster from the condition though they had higher serum NO level than CLP rats.

\section{Acknowledgements}

The authors declare that they have no competing interests. The authors would like to thank the Guangdong Institute of Gastroenterology at the Sixth Affiliated Hospital of Sun Yat-sen University for help with experimental facilities.

Supported by Science and Technology Planning Project of Guangdong Province (2013B021800123) and Techpool Fund (01201128), China.

\section{References}

[1] Levy, M.M., Fink, M.P., Marshall, J.C., Abraham, E., Angus, D., Cook, D., Cohen, J., Opal, S.M., Vincent, J.L. and Ramsay, G. (2003) 2001 SCCM/ESICM/ACCP/ATS/SIS International Sepsis Definitions Conference. Intensive Care Medicine, 29, 530-538. https://doi.org/10.1007/s00134-003-1662-x

[2] Shimaoka, M. and Park, E.J. (2008) Advances in Understanding Sepsis. European Journal of Anaesthesiology. Supplement, 25, 146-153. https://doi.org/10.1017/S0265021507003389

[3] Kaukonen, K.M., Bailey, M., Suzuki, S., Pilcher, D. and Bellomo, R. (2014) Mortality Related to Severe Sepsis and Septic Shock among Critically Ill Patients in Australia and New Zealand, 2000-2012. Journal of the American Medical Association, 311, 1308-1316. https://doi.org/10.1001/jama.2014.2637

[4] Dellinger, R.P., Levy, M.M., Rhodes, A., Annane, D., Gerlach, H., Opal, S.M., Sevransky, J.E., Sprung, C.L., Douglas, I.S., Jaeschke, R., et al. (2013) Surviving Sepsis Campaign: International Guidelines for Management of Severe Sepsis and Septic Shock: 2012. Critical Care Medicine, 41, 580-637. 
https://doi.org/10.1097/CCM.0b013e31827e83af

[5] Dellinger, R.P., Levy, M.M., Carlet, J.M., Bion, J., Parker, M.M., Jaeschke, R., Reinhart, K., Angus, D.C., Brun-Buisson, C., Beale, R., et al. (2008) Surviving Sepsis Campaign: International Guidelines for Management of Severe Sepsis and Septic Shock: 2008. Critical Care Medicine, 36, 296-327. https://doi.org/10.1097/01.CCM.0000298158.12101.41

[6] Dellinger, R.P., Carlet, J.M., Masur, H., Gerlach, H., Calandra, T., Cohen, J., Gea-Banacloche, J., Keh, D., Marshall, J.C., Parker, M.M., et al. (2004) Surviving Sepsis Campaign Guidelines for Management of Severe Sepsis and Septic Shock. Critical Care Medicine, 32, 858-873. https://doi.org/10.1097/01.CCM.0000117317.18092.E4

[7] Moore, L.J., McKinley, B.A., Turner, K.L., Todd, S.R., Sucher, J.F., Valdivia, A., Sailors, R.M., Kao, L.S. and Moore, F.A. (2011) The Epidemiology of Sepsis in General Surgery Patients. Journal of Trauma-Injury Infection \& Critical Care, 70, 672-680. https://doi.org/10.1097/TA.0b013e31820e7803

[8] Czura, C.J. (2011) "Merinoff Symposium 2010: Sepsis"-Speaking with One Voice. Molecular Medicine, 17, 2-3. https://doi.org/10.2119/molmed.2010.00001.commentary

[9] Shiramizo, S.C., Marra, A.R., Durao, M.S., Paes, A.T., Edmond, M.B. and Pavao dos Santos, O.F. (2011) Decreasing Mortality in Severe Sepsis and Septic Shock Patients by Implementing a Sepsis Bundle in a Hospital Setting. PLoS One, 6, e26790. https://doi.org/10.1371/journal.pone.0026790

[10] Huet, O., Dupic, L., Harrois, A. and Duranteau, J. (2011) Oxidative Stress and Endothelial Dysfunction during Sepsis. Frontiers in Bioscience, 16, 1986-1995. https://doi.org/10.2741/3835

[11] Fraunberger, P., Drexel, H. and Walli, A.K. (2010) Pathophysiology of Sepsis and Possible Influence of Statins. Deutsche Medizinische Wochenschrift, 135, 2128-2132. https://doi.org/10.1055/s-0030-1267491

[12] Remick, D.G. (2007) Pathophysiology of Sepsis. American Journal of Pathology, 170, 1435-1444. https://doi.org/10.2353/ajpath.2007.060872

[13] Navarrete, M.L., Cerdeno, M.C., Serra, M.C. and Conejero, R. (2013) Mitochondrial and Microcirculatory Distress Syndrome in the Critical Patient. Therapeutic Implications. Medicina Intensiva, 37, 476-484.

[14] Buras, J.A., Holzmann, B. and Sitkovsky, M. (2005) Animal Models of Sepsis: Setting the Stage. Nature Reviews Drug Discovery, 4, 854-865. https://doi.org/10.1038/nrd1854

[15] Maier, S., Traeger, T., Entleutner, M., Westerholt, A., Kleist, B., Hser, N., Holzmann, B., Stier, A., Pfeffer, K. and Heidecke, C.-D. (2004) Cecal Ligation and Puncture versus Colon Ascendens Stent Peritonitis: Two Distinct Animal Models for Polymicrobial Sepsis. Shock, 21, 505-512. https://doi.org/10.1097/01.shk.0000126906.52367.dd

[16] Yoneyama, S., Terashima, H., Yamaguchi, R., Tadano, S. and Ohkohchi, N. (2013) The Manner of the Inflammation-Boosting Effect Caused by Acute Hyperglycemia Secondary to Overfeeding and the Effects of Insulin Therapy in a Rat Model of Sepsis. Journal of Surgical Research, 185, 380-387.

[17] Ziaja, M. (2012) Sepsis and Septic Encephalopathy: Characteristics and Experimental Models. Folia Neuropathologica, 50, 231-239. https://doi.org/10.5114/fn.2012.30523

[18] Wichterman, K.A., Baue, A.E. and Chaudry, I.H. (1980) Sepsis and Septic Shock-A 
Review of Laboratory Models and a Proposal. Journal of Surgical Research, 29, 189-201.

[19] Zantl, N., Uebe, A., Neumann, B., Wagner, H., Siewert, J.R., Holzmann, B., Heidecke, C.D. and Pfeffer, K. (1998) Essential Role of Gamma Interferon in Survival of Colon Ascendens Stent Peritonitis, a Novel Murine Model of Abdominal Sepsis. Infection and Immunity, 66, 2300-2309.

[20] Traeger, T., Koerner, P., Kessler, W., Cziupka, K., Diedrich, S., Busemann, A., Heidecke, C.D. and Maier, S. (2010) Colon Ascendens Stent Peritonitis (CASP)-A Standardized Model for Polymicrobial Abdominal Sepsis. Journal of Visualized EXperiments, No. 46, 2299. https://doi.org/10.3791/2299

[21] Hubbard, W.J., Choudhry, M., Schwacha, M.G., Kerby, J.D., Rue, L.W., Bland, K.I. and Chaudry, I.H. (2005) Cecal Ligation and Puncture. Shock, 24, 52-57. https://doi.org/10.1097/01.shk.0000191414.94461.7e

[22] Latief, N., Anand, S., Lingaraju, M.C., Balaganur, V., Pathak, N.N., Kalra, J., Kumar, D., Bhadoria, B.K. and Tandan, S.K. (2015) Effect of Trimeric Myricetin Rhamnoside (TMR) in Carrageenan-Induced Inflammation and Caecal Ligation and Puncture-Induced Lung Oxidative Stress in Mice. Phytotherapy Research, 29, 1798-1805. https://doi.org/10.1002/ptr.5446

[23] Wahab, F., Santos-Junior, N.N., de Almeida Rodrigues, R.P., Costa, L.H., Catalao, C.H. and Rocha, M.J. (2015) Interleukin-1 Receptor Antagonist Decreases Hypothalamic Oxidative Stress during Experimental Sepsis. Molecular Neurobiology, 53, 3992-3998.

\section{Submit or recommend next manuscript to SCIRP and we will provide best service for you:}

Accepting pre-submission inquiries through Email, Facebook, LinkedIn, Twitter, etc. A wide selection of journals (inclusive of 9 subjects, more than 200 journals)

Providing 24-hour high-quality service

User-friendly online submission system

Fair and swift peer-review system

Efficient typesetting and proofreading procedure

Display of the result of downloads and visits, as well as the number of cited articles

Maximum dissemination of your research work

Submit your manuscript at: http://papersubmission.scirp.org/

Or contact aid@scirp.org 